\section{HORMIGONES REFORZADOS CON FIBRAS DE ACERO}

\author{
M. Fernández Cánovas \\ Dr. Ing. de Construcción \\ IETcC
}

$684-9$

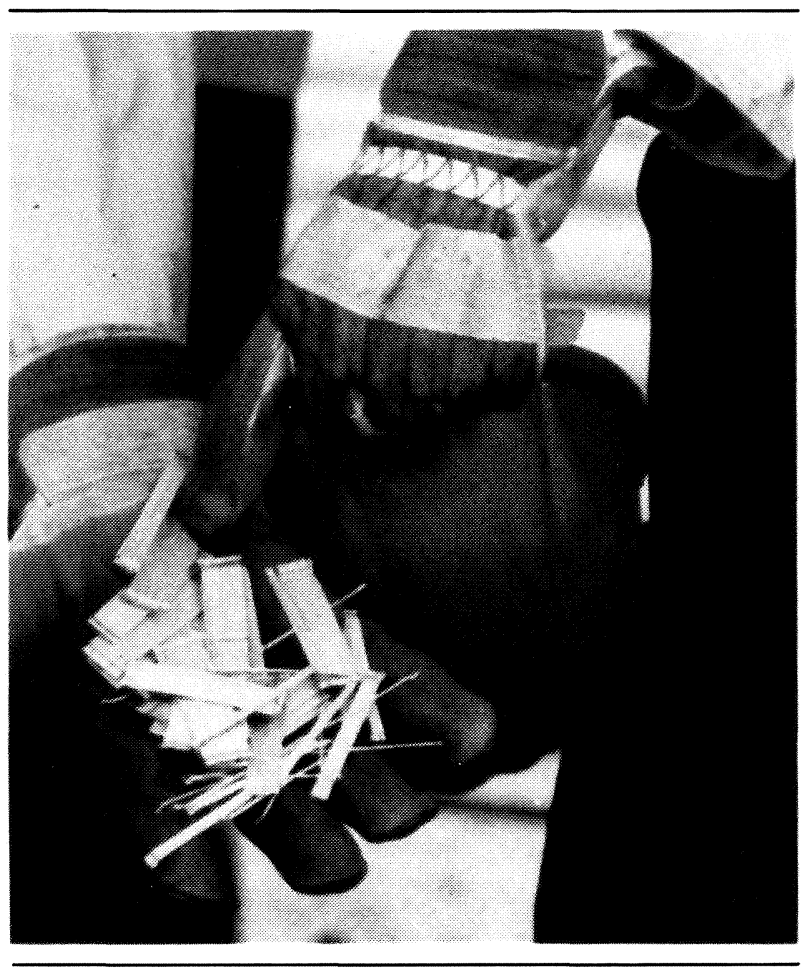

INTRODUCCION

Durante las tres últimas décadas se ha producido un gran desarrollo en la industria de la construcción, desarrollo que ha alcanzado, no sólo a las técnicas de diseño y cálculo, sino también a la tecnologia del hormigón $y$, por supuesto, al propio hormigón. Y es lógico que esto sea asi, pues refiriéndonos concretamente al caso del hormigón hemos de decir que, a pesar de su larga vida, pocos avances ha experimentado hasta nuestros dias este noble material.

El hormigón -el material más empleado en nuestras obras de ingenieria- es un compendio de virtudes pero con grandes lacras; es pesado, tiene una relación muy baja entre su resistencia a tracción y compresión; su relación peso-resistencia es excesivamente alta; su estabilidad de volumen deja mucho que desear, siendo su inestabilidad fuente de importantes problemas patológicos. Su capacidad para absorber energia antes de la rotura es baja, su durabilidad es muy sensible a su proyecto y ejecución, etc. Sin embargo, y a pensar de estos inconvenientes, el hormigón tiene tantas ventajas y tantos argumentos a su favor que se puede considerar, sin duda, el rey de los materiales de construcción.

Ultimamente han sido muchos y grandes los esfuerzos para sacar al hormigón de su sueño de siglos; de siglos porque hay muestras de hormigones primitivos que datan de 5.000 años antes de J.C. y que tenian resistencias suficientes como para ser considerados materiales estructurales; estos esfuerzos a que me refiero han estado encaminados a mejorar el hormigón, bien mediante el empleo de nuevos cementos, bien con la utilización de nuevas técnicas de puesta en obra que permitieran rebajar la relación agua-cemento mejorando, al mismo tiempo, la compacidad, bien mediante el empleo de nuevas adiciones como los superplastificantes o por último, mediante tecnologias nuevas que permitiesen lograr hormigones más isótropos y en los que inconvenientes, como los antes apuntados, quedasen reducidos. Dentro de estas nuevas tecnologias se encuentra en un lugar muy destacado el empleo de fibras de acero para reforzar o armar al hormigón.

\section{FIBRAS}

El empleo de fibras para mejorar la isotropia de un material no es algo desconocido. Los adobes de barro cocidos al sol y armados con paja ya se empleaban en Caldea; hasta hace poco hemos visto utilizar pelos de cabra o de caballo para armar el yeso; el fibrocemento no es otra cosa que una pasta de cemento a la que se ha añadido del 8 al $16 \%$ de fibras de asbesto para incrementar la resistencia a flexotracción de 2 a 4 veces la de la matriz. Al mismo hormigón armado podriamos considerarlo, en el limite, como un hormigón de gruesas fibras orientadas.

Las fibras empleadas en el hormigón reforzado son discontinuas, presentando una distribución discreta y uniforme que confiere al material una gran isotropia y homogeneidad. La efectividad de la acción reforzante y la eficacia en la transmisión de tensiones depende de muchos factores pero, especialmente, de la naturaleza y del tipo de fibra empleado.

Las fibras actualmente empleadas pueden ser minerales, orgánicas y metálicas. 
Entre las minerales cabe distinguir las de asbesto y las de vidrio. Las fibras de asbesto o amianto empleadas en el fibrocemento tienen el inconveniente de absorber grandes cantidades de agua, con lo cual al aumentar la relación agua-cemento exigen gran cantidad de fibras y de cemento para obtener resistencias apreciables; la distribución uniforme de las fibras es dificil de conseguir. No todos los paises poseen asbesto y, por último, se ha demostrado que el asbesto da "asbestosis". Las fibras de vidrio están sustituyendo, en sus aplicaciones, al asbesto; sin embargo, estas fibras tienen el inconveniente de ser atacadas por los álcalis del cemento, lo que da lugar a una degradación con el tiempo de las resistencias. Este inconveniente se evita mediante el revestimiento de las fibras con resinas tipo epoxi o con el empleo de fibras especiales con óxido de zirconio. Ambos sistemas encarecen las fibras.

Las fibras orgánicas pueden ser de algodón, rayón, poliéster, polipropileno, polietileno y nilón. Las tres primeras hay que desecharlas, ya que son atacables por los álcalis. Las más empleadas son las de nilón, polietileno y polipropileno; sin embargo, debido al bajo módulo de elasticidad que poseen, no tienen interés en los hormigones reforzados debido a la gran deformabilidad que les confieren y a no aumentar sensiblemente la resistencia a tracción por fallar la adherencia con la pasta de cemento. No obstante, algunas veces se utilizan para mejorar la resistencia al impacto de hormigones.

Las fibras metálicas, concretamente las de acero, son las que más se emplean en el refuerzo de hormigones por ser las más eficaces y económicas. El acero posee un módulo de elasticidad diez veces superior al del hormigón; las fibras de acero detentan una buena adherencia a la pasta, alto alargamiento de rotura $y$, por otra parte, son fáciles de mezclar.

Las fibras de acero pueden obtenerse por diferentes métodos; el más común consiste en fabricarlas por corte de alambre trefilado, de acero, de bajo contenido en carbono. El diámetro de los alambres está comprendido entre 0,25 y $0,80 \mathrm{~mm}$. La longitud de las fibras puede ser muy variable, oscilando entre 10 y $75 \mathrm{~mm}$.

A efectos de comparación de unas fibras, con respecto a otras, se ha establecido un parámetro numérico denominado "aspecto". El aspecto o esbeltez de una fibra es la relación que existe entre la longitud de la misma y su diámetro equivalente, es decir, el diámetro del circulo cuya sección es equivalente a la superficie de la fibra. Los aspectos normales oscilan entre 30 y 150.

Los principales efectos que trae consigo la incorporación de fibras de acero a los hormigones podemos resumirlos en los siguientes:
- Mejora del comportamiento a flexotracción.

- Incremento de la resistencia a rotura.

- Reducción de la deformación bajo cargas mantenidas.

- Aumento de la resistencia a tracción.

- Fuerte incremento en la resistencia a impacto y choque.

- Gran resistencia a fatiga dinámica.

- Fisuración controlada.

- Aumento de la durabilidad.

\section{DOSIFICACION, AMASADO Y PUESTA EN OBRA}

Los hormigones reforzados con fibras de acero están formados, esencialmente, por: un conglomerante hidráulico; áridos finos y gruesos; agua; fibras discontinuas cuya misión es contribuir a mejorar determinadas caracteristicas de los hormigones $y$, eventualmente, aditivos.

Las fibras en una mezcla de hormigón actúan como inclusiones rigidas con una gran área superficial y una geometría diferente a la de los áridos. No es de extrañar, por tanto, que se reduzca la docilidad de la mezcla, salvo que se hagan las oportunas correcciones a la dosificación.

Para que cada fibra sea efectiva precisa estar completamente embebida dentro de la mezcla; esto obliga a que la proporción de elementos finos a gruesos tenga que ser la adecuada, generalmente, con mayor proporción de finos que en un hormigón convencional. Los hormigones convencionales requieren entre el 25 y el $35 \%$ de pasta con respecto al volumen total, mientras que un hormigón armado con fibras precisa del 35 al $45 \%$ dependiendo del aspecto y volumen de fibras empleado.

Es absolutamente imprescindible - cualquiera que sea el método utilizado- obtener una dispersión uniforme de las fibras y eliminar los peligros de segregación y de formación de bolas o "erizos" de fibras. La segregación y formación de bolas están relacionadas con muchos parámetros, principalmente con el aspecto, el porcentaje de fibras, tamaño máximo del árido, granulometría, relación agua-cemento y sistema de mezclado.

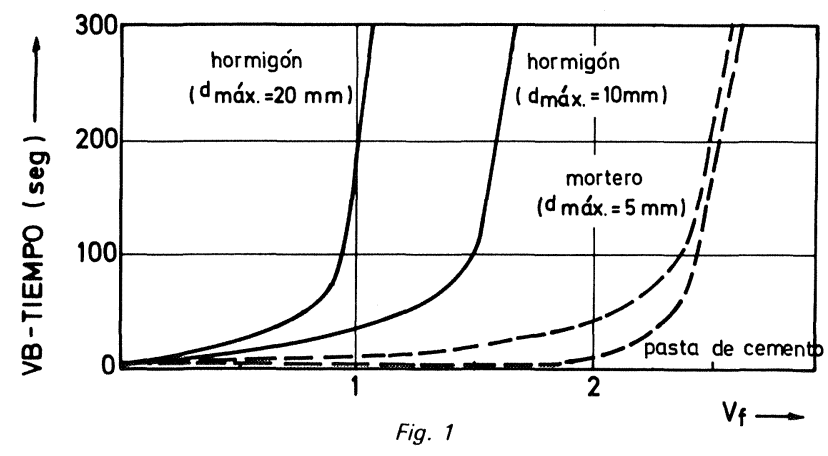




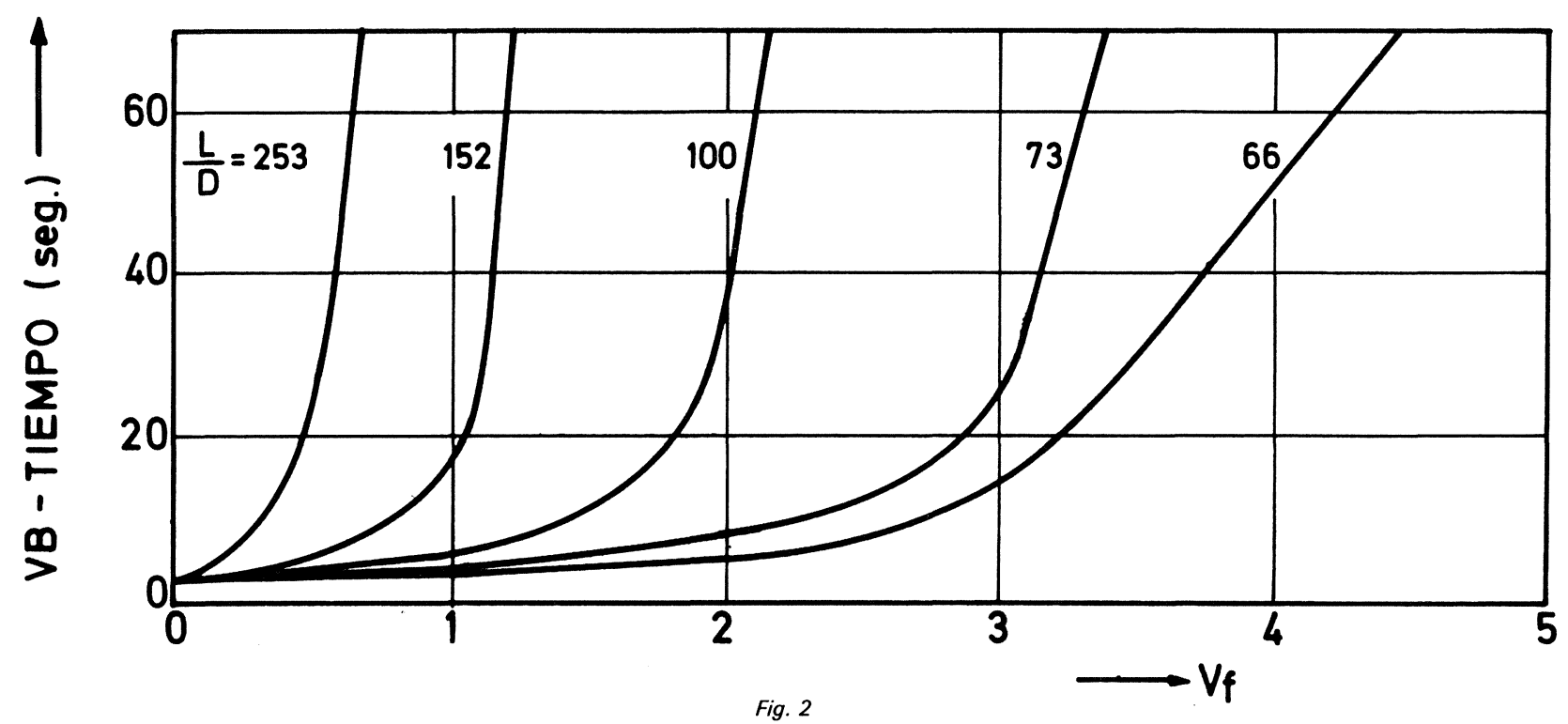

Se ha comprobado que para obtener mezclas uniformes el aspecto debe ser, como máximo, de 100. También se ha podido comprobar que los hormigones son difíciles de trabajar cuando la cantidad de fibras de acero sobrepasa el $2 \%$ en volumen absoluto de pasta, aunque en morteros pueda llegarse al $4 \%$. Estas cifras pueden aumentarse siempre que se trabaje con aspectos muy reducidos, lo que trae consigo una disminución de la eficacia del refuerzo.

La buena docilidad de las mezclas y la eliminación de la formación de bolas aconsejan no emplear áridos de tamaño superior a $20 \mathrm{~mm}$, lo cual no es un grave inconveniente, ya que para muchas aplicaciones éste es un tamaño ideal. En la figura 1 se muestra cómo influye en la docilidad o trabajabilidad el tamaño máximo del árido, y asi se ve que para una consistencia Vebe de $100 \mathrm{seg}$., con fibras de aspecto 100 , en morteros, con arena de $5 \mathrm{~mm}$, se puede llegar a contenidos de fibras del $2,5 \%$ en volumen de hormigón; con hormigones de áridos de tamaño máximo $10 \mathrm{~mm}$ no se debe pasar del $1,5 \%$ de fibras, y con hormigones de áridos de $20 \mathrm{~mm}$ este contenido debe limitarse a prácticamente al $1 \%$; todo ello en el supuesto de que se estén empleando fibras rectas.

En la figura 2, se puede apreciar la gran influencia que tiene el aspecto o esbeltez de la fibra en la docilidad. Asi se comprueba que, con fibras rectas de aspecto igual a 100 , si queremos mantener un tiempo Vebe de $40 \mathrm{seg}$, se pueden incorporar a la mezcla el 2 por 100 en volumen de fibras, mientras que si las fibras poseen aspectos mayores se obtienen hormigones menos trabajables o dóciles, salvo que se reduzca el porcentaje de fibras incorporado. Así, para 152 de aspecto, el volumen admisible de fibras quedaria reducido al $1,2 \%$, mientras que, por el contrario, aspectos de 73 permiten la incorporación de hasta un 3,2\% de fibras.
Por otra parte se ha visto que para un diámetro y volumen de fibras dado, el tiempo Vebe se incrementa linealmente con el aumento de la longitud de las fibras, de tal forma que la docilidad es tanto más pequeña cuanto más reducidos son los diámetros de las fibras.

Los hormigones de fibras de acero experimentan, por tanto, una disminución en la docilidad cuando aumenta el volumen de fibras, lo que implica que para asegurar la dispersión de las mismas hay que emplear relaciones agua-cemento entre 0,5 y 0,6 , con dosificaciones de cemento altas, que pueden llegar hasta los $500 \mathrm{~kg}$ por $\mathrm{m}^{3}$; puede disminuirse la cantidad de cemento a utilizar empleando cenizas volantes, ya que lo que realmente importa es que las fibras queden envueltas en pasta. Se logra una mezcla económica mezclando una cantidad de cenizas que sea mitad de la cantidad de cemento e incorporando un plastificante. La presencia de cenizas, por otra parte, retrasa el fraguado del hormigón, ayudando así a la puesta en obra y acabado, y suministrando una mezcla con alto contenido en pasta baja en cemento. Nosotros hemos conseguido hormigones de $400 \mathrm{kp} / \mathrm{cm}^{2}$ de resistencia característica empleando $450 \mathrm{~kg}$ de cemento PA-350, con relación agua-cemento de 0,45 e incorporando un $1 \%$ de superplastificante. Los áridos eran de $20 \mathrm{~mm}$ y la dosificación de fibras de $60 \mathrm{~kg}$ por $\mathrm{m}^{3}$, lo que equivale al $0,75 \%$ en volumen, obteniendo un cono de $10 \mathrm{~cm}$. Este hormigón lo hemos utilizado en pavimentos de puentes en pistas.

En general no se presentan problemas de segregación ni de formación de erizos cuando los diámetros de las fibras están comprendidos entre 0,4 y $0,8 \mathrm{~mm}$ y las longitudes entre 25 y $70 \mathrm{~mm}$, y se emplean en cantidades que no exceden del $1,5 \%$ en volumen. Con cantidades superiores empiezan a surgir problemas en cuanto a docilidad, y la formación de bolas agrava la situación dando lugar a 
masas heterogéneas con zonas muy pobres o muy ricas en fibras. Las fibras de diámetros inferiores a $0,5 \mathrm{~mm}$, en proporciones mayores del $1 \%$, son muy propensas a la formación de bolas, mientras que los diámetros mayores permiten trabajar con porcentajes más elevados.

Cuando una dosificación está bien realizada no existen problemas en el amasado y en la puesta en obra.

El amasado puede realizarse en central o en la misma obra. En central basta con adicionar las fibras a la masa y amasar el conjunto durante un minuto o minuto y medio hasta conseguir la dispersión total de las fibras. En obra se añaden al camión-hormigonera y se mantiene girando la cuba a toda velocidad durante un minuto y medio. Los dos sistemas son buenos, aunque nosotros preferimos el primero debido a que de la central sale el hormigón con las caracteristicas requeridas, mientras que en obra, a veces, hay que hacer correcciones en el agua de amasado, lo que suele ser más impreciso.

Una vez conseguida la docilidad adecuada a los medios de puesta en obra disponibles, el hormigón de fibras se coloca por los sistemas tradicionales, incluido el bombeado, sin ningún problema. La compactación, tanto con pervibradores como con reglas vibrantes, se realiza con suma facilidad. Igualmente, el empleo de extendedoras "slipform" de pavimentos es sumamente interesante en la colocación de hormigón en grandes extensiones de pavimentos industriales, carreteras o aeropuertos.

\section{MECANISMO DE REFUERZO}

Para entender cómo se realiza el refuerzo del hormigón por las fibras hay que examinar la curva tensión-deformación frente a flexión del hormigón tradicional y del reforzado con fibras de acero (Figura 3). Si observamos la curva del hormigón reforzado vemos que ésta es más o menos lineal, hasta llegar al punto que corresponde a la itensión de primera fisuran; luego la curva se mueve buscando un máximo en otro punto más elevado llamado "última tensión de rotura". En un hormigón tradicional, una vez alcanzada la tensión de primera fisura, se llega a la máxima tensión y ocurre la rotura. En el reforzado con fibras, la primera fisura tiene lugar para tensiones iguales o ligeramente superiores a la tensión máxima del convencional, empezando a ejercerse el efecto de armado de las fibras por encima de este punto y gracias al esfuerzo compuesto que se produce, y al que colabora el que el acero tenga un módulo de elasticidad diez veces superior al del hormigón. Por otra parte la linealidad, hasta alcanzar la primera fisura o limite elástico, puede ser perfecta o sufrir desplazamientos si el volumen de fibras es elevado.

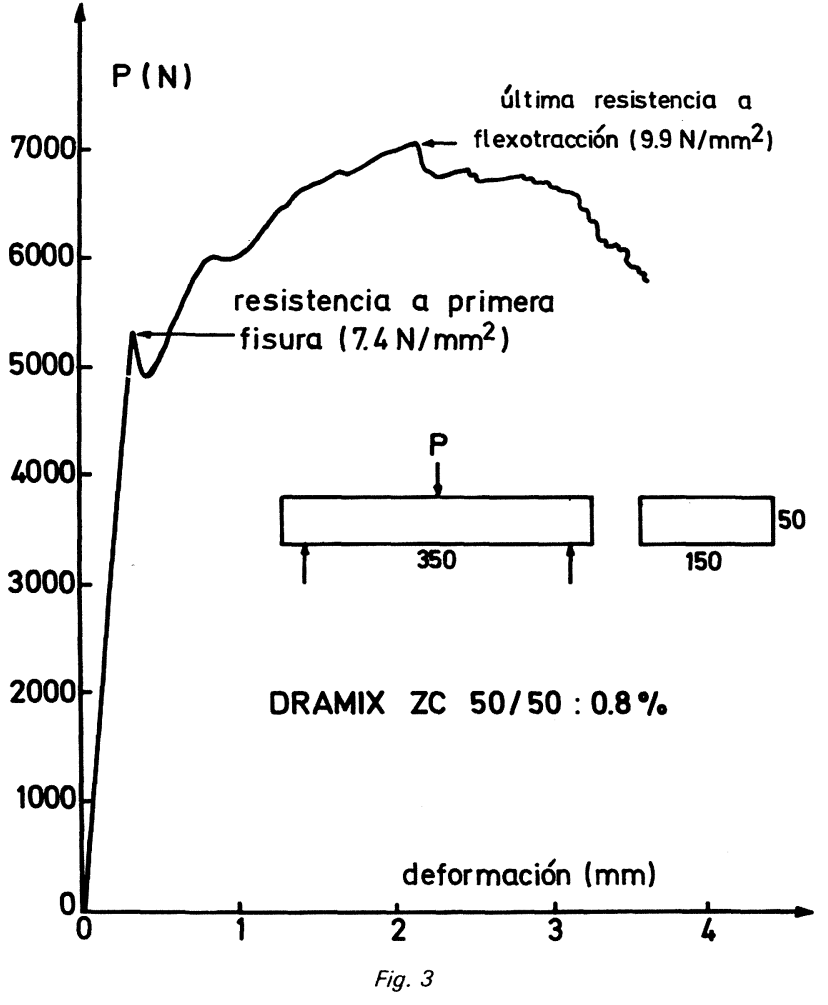

En el momento en que se inicia la fisuración en la zona traccionada de una viga de ensayo (Figura 4) comienzan a trabajar las fibras y continúan haciéndolo hasta que rompen por tracción o deslizan por pérdida de adherencia (Figura 5). Aunque las fibras están orientadas en todas direcciones, dentro de la masa del hormigón, siempre hay algunas que actúan de puentes o lañas entre las dos partes del hormigón que dividen las fisuras, pudiendo transmitir los esfuerzos con ángulos muy variables de acuerdo con la orientación que posean con respecto al plano de la fisura.

La resistencia última del hormigón de fibras es inferior a la que poseería si todo el volumen de fibras estuviese en forma de barras convencionales armando la zona traccionada; en general oscila entre el 0,25 y 0,35 de la resistencia con armado convencional. Esto es lógico si se tiene en cuenta la orientación arbitraria de las fibras y su dispersión en todo el volumen de la viga, asi como la pérdida de adherencia debida a la menor longitud de las fibras, si bien este efecto se mejora con el empleo de fibras de formas especiales en sus extremos a fin de crear anclajes, o con fibras de mayores aspectos, aunque esto crea, como hemos visto, problemas en la docilidad, salvo que también se utilicen medidas especiales como veremos más adelante.

Un hormigón reforzado con fibras tiene una resistencia postfisuración muy elevada como puede apreciarse en la curva tensión-deformación. Por otra parte, al ser el área comprendida bajo la curva proporcional a la cantidad de energia absorbida 

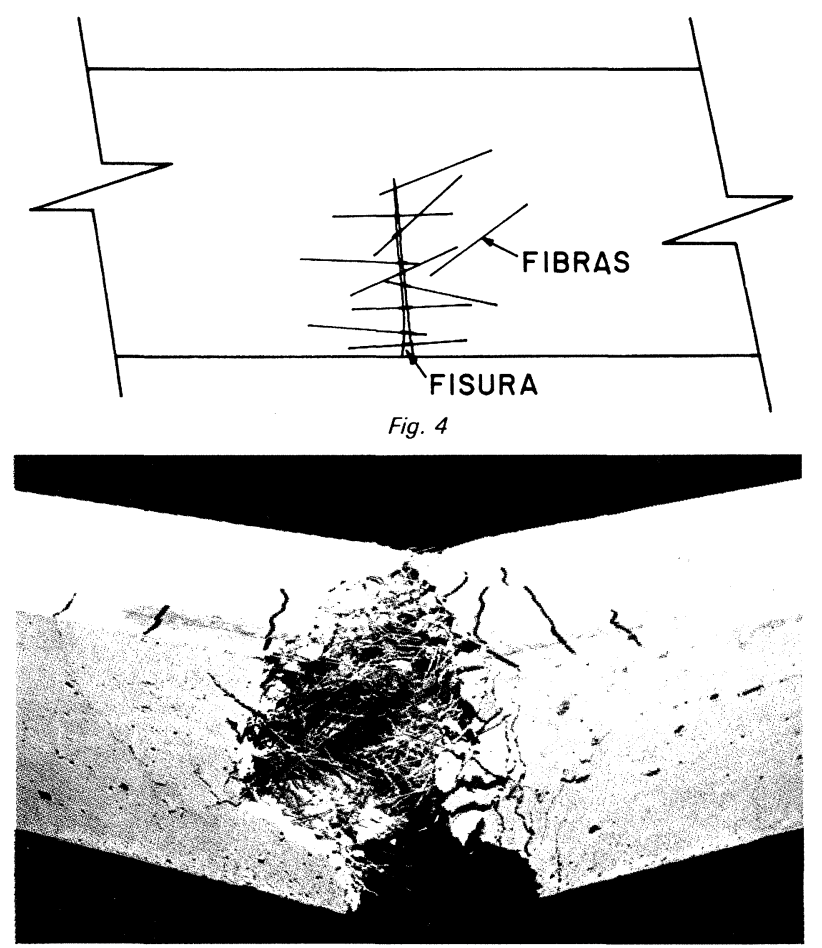

Fig. 5

antes de la rotura, ésta nos va a dar idea de la gran tenacidad de estos hormigones. El indice de tenacidad es una medida de la capacidad de absorción de energía del hormigón de fibras y compara la energía requerida para flectar una vigaprobeta de unas dimensiones normalizadas, sometida a carga centrada, hasta conseguir que la flecha en el centro de la probeta tenga un valor determinado, con la energía necesaria para conseguir igual efecto en una viga-probeta de hormigón convencional. El indice de tenacidad de hormigones con volúmenes de fibras comprendidos entre el 1 y $2 \%$ oscila entre 12 y 45 , mientras que el de un hormigón tradicional es la unidad.

La energía absorbida por un hormigón de fibras depende de la cantidad, longitud, configuración, resistencia y ductilidad de las fibras empleadas, así como de otros factores tales como: contenido de cemento, cantidad y tamaño de los áridos, relación agua-cemento, edad y curado del hormigón.

Para un hormigón armado con fibras puede definirse el "límite de proporcionalidad" como la carga bajo la cual su comportamiento es totalmente elástico. Por debajo de este límite la influencia de la fisuración de la matriz de hormigón puede despreciarse; se puede suponer, por tanto, que el hormigón de fibras de acero se comporta elásticamente hasta este límite, como si se tratara de un hormigón convencional. Dicho límite puede coincidir con el "limite elástico" o de "primera fisura".

Dado que el acero tiene un módulo de elasticidad, que suele ser diez veces superior al del hormigón, aumentando el volumen de fibras incrementamos la carga correspondiente al punto en que la curva se desvia de la linealidad. Sin embargo, como las fibras están aleatoriamente distribuidas, su influencia para el mismo volumen de acero será menor que en el armado convencional.

Una idea aproximada de la influencia de las fibras, en las propiedades elásticas del hormigón, se desprende de la ecuación:

$$
\mathrm{E}_{c}=\mathrm{E}_{f} \cdot \mathrm{v}_{f}+\mathrm{E}_{m} \cdot \mathrm{v}_{m}
$$

en la que: $E_{c}, E_{f}$ y $E_{m}$ son los módulos de elasticidad del hormigón compuesto, de las fibras y de la matriz, siendo $v_{f} y v_{m}$ las fracciones en volumen de la matriz y fibras, respectivamente.

Esta ecuación es estrictamente válida para mezclas con fibras continuas y comportamiento elástico de los componentes, sin deslizamiento entre fibras y hormigón. Dado que las fibras tienen longitud finita puede haber alguna microfisura antes del límite elástico a causa de algún fallo de adherencia en las fibras; por tanto, esta ecuación es únicamente una solución límite para el módulo de elasticidad y límite elástico en el hormigón reforzado con fibras.

Algunos autores han realizado aproximaciones teóricas para predecir la influencia de la orientación de las fibras en las propiedades elásticas de los hormigones resultantes, teniendo en cuenta la existencia de una variable muy importante que influye mucho en estos resultados: el factor de eficacia. Este factor se define como el porcentaje del volumen total de fibras que contribuyen, en una determinada dirección, a absorber esfuerzos. El factor de eficacia puede tomar valores que oscilan entre el 40 y el $80 \%$, dependiendo del espesor de la pieza.

En las proximidades de la máxima carga en flexión, parte de la sección transversal de la pieza se agrieta y algunas de las fibras pueden sufrir deslizamientos parciales dependiendo su cuantía, entre otras cosas, de que lleven o no anclajes en sus extremos. Debido a esto no es posible predecir, racionalmente, la carga de rotura del hormigón de fibras; sin embargo, basándose en los resultados experimentales y en las teorias de composición, pueden lograrse aproximaciones empíricas bastante acertadas.

Los factores más importantes que influyen en la carga máxima son dos: è porcentaje en volumen de fibras y el aspecto de las mismas. También se ha comprobado que si se evita el fenómeno de segregación, el incremento del porcentaje de fibras da lugar a un aumento, de forma más o menos lineal, de la carga de rotura del hormigón. 
Basados en estas observaciones, la carga de rotura que proponen Shah, Surendra, Rangan y Vijaya es:

$$
\sigma_{c}=A \cdot \sigma_{m}\left(1-v_{f}\right)+B \cdot v_{f} \cdot \frac{\ell}{d}
$$

expresión en la que $\sigma_{c}$ y $\sigma_{m}$ son, respectivamente, la tensión de rotura del hormigón de fibras y la de la matriz de hormigón; $\ell$ la longitud de las fibras y $d$ su diámetro; $v_{f}$ el volumen de fibras; $A$ y $B$ son dos constantes.

El primer término del segundo miembro representa la contribución de la matriz de hormigón a la carga máxima. El máximo valor de $A$ es la unidad. La constante B depende de la aleatoriedad de la distribución de las fibras y de la adherencia entre fibras y matriz; en su valor interviene la forma de las fibras y el que lleven o no extremos conformados para mejorar el anclaje.

Swamy - uno de los investigadores que más ha trabajado en este campo- propone las siguientes expresiones para las tensiones de primera fisura y rotura en hormigones con fibras rectas:

$$
\begin{aligned}
& \sigma_{F}=0,834 \sigma_{m}\left(1-\mathrm{v}_{f}\right)+2,00 \mathrm{v}_{f} \frac{\ell}{\mathrm{d}} \\
& \sigma_{c}=0,970 \sigma_{m}\left(1-\mathrm{v}_{f}\right)+2,00 \mathrm{v}_{f} \frac{\ell}{\mathrm{d}}
\end{aligned}
$$

\section{FIBRAS DE EXTREMOS CONFORMADOS $Y$ ENCOLADAS}

Anteriormente se ha indicado que la resistencia última de un hormigón de fibras es una función de la forma:

$$
\sigma_{c}=\mathrm{A}+\mathrm{B} \cdot \mathrm{v}_{f} \cdot \frac{\mathrm{l}}{\mathrm{d}}
$$

es decir: a igualdad de otros factores, $\sigma_{c}$ es proporcional al volumen de fibras y al aspecto, dependiendo además de un coeficiente $B$ que, a su vez, depende del tipo de anclaje de las fibras (entre otros factores) siendo tanto más alto cuanto mayor sea el efecto de anclaje en los extremos de la fibra.

Por otra parte hemos señalado, con anterioridad, la incompatibilidad existente entre el aumento de volumen de fibras y la docilidad de la mezcla, de forma que a mayor $v_{f}$ corresponde menor trabajabilidad y más peligro de formación de erizos. Por tanto, si se desean buenas resistencias, se puede aumentar el valor del aspecto $\frac{\ell}{d} \sin$ necesidad de elevar excesivamente el valor de $v_{f}$ con lo cual, además, se tendrán hormigones más económicos.

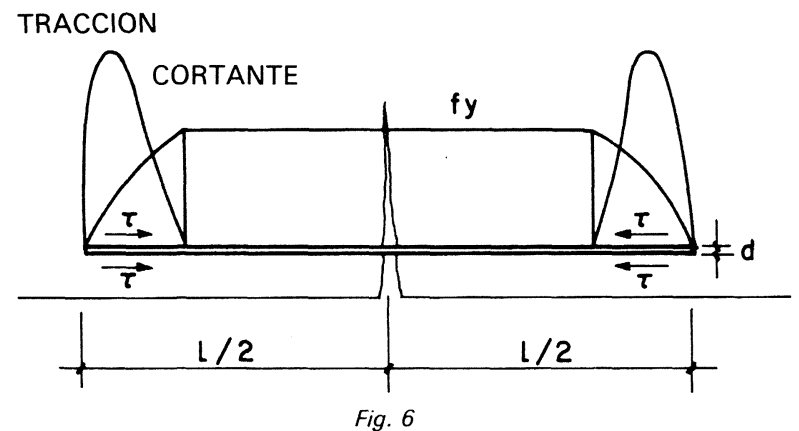

Sin embargo, hemos visto que el aumento del aspecto por encima de.determinados límites trae como consecuencia una disminución de docilidad y un fuerte peligro de formación de bolas.

Las fibras Dramix han solucionado estos problemas de la siguiente forma:

- Aumentar el valor de B mediante la conformación de los extremos de las fibras, justo en la zona donde el valor de la tensión de deslizamiento es más fuerte.

- Una fibra debe llegar al agotamiento simultáneo por deslizamiento y tracción; esto exige, de acuerdo con la figura 6 , que se cumpla:

$$
\pi \cdot \mathrm{d} \cdot \frac{\ell}{2} \tau_{m}=\frac{\pi \cdot \mathrm{d}^{2}}{4} \mathrm{f}_{y}
$$

es decir:

$$
\frac{\ell}{d}=\frac{f_{y}}{2 \cdot \tau_{m}} .
$$

Si suponemos fibras de acero trefilado con $f_{y}=12.000 \mathrm{kp} / \mathrm{cm}^{2}$ y $\tau_{m}=25 \mathrm{kp} / \mathrm{cm}^{2}$ se tiene un aspecto de $240 \mathrm{y}$, como éste es excesivamente alto (hemos indicado que no debe pasar de 100 por razones de docilidad), habría que ir a fibras de menores aspectos que deslizarian antes de alcanzar su rotura. Si las fibras tienen los extremos conformados, como es el caso de las Dramix, el valor de $\tau_{m}$ crece notablemente y el aspecto se reduce, permitiendo aprovechar al máximo la capacidad resistente del acero.

- En el amasado, y fundamentalmente en la primera parte del mismo, si las fibras poseen un aspecto elevado hacen a la masa poco trabajable, favoreciendo además la formación de bolas. Las fibras Dramix evitan este inconveniente al venir adosadas unas a otras por medio de un adhesivo soluble en el agua de amasado y compatible con el cemento, dando lugar a peines de unas 25 fibras (Fig. 7); de esta forma, si llamamos $D_{e}$ al diámetro de la sección circular equivalente a la sección del peine de 


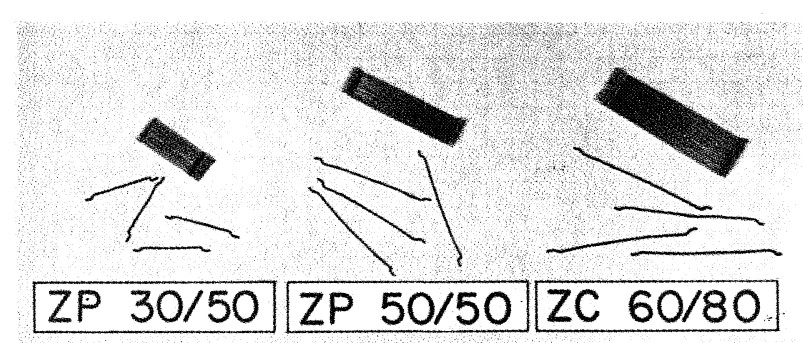

Fig. 7

$\mathrm{n}=25$ fibras, y d al diámetro de una de las fibras aisladas, tendremos:

$$
\mathrm{D}_{e}^{2}=\mathrm{n} \cdot \mathrm{d}^{2} ; \mathrm{D}_{e}=\sqrt{25} \cdot \mathrm{d}=5 \cdot \mathrm{d}
$$

con lo que el aspecto equivalente al introducir las fibras será:

$$
\frac{l}{D_{e}}=\frac{\ell}{5 \cdot d}
$$

es decir, la quinta parte del aspecto de una fibra aislada, con lo cual, si éstas tienen un aspecto de 100 , durante la parte critica del amasado se comportan como si tuviesen un aspecto de 20 , dando lugar a que el hormigón se trabaje con suma facilidad, e incluso permitiendo, si se desean altas resistencias, aumen$\operatorname{tar} \mathrm{v}_{f}$ a valores que no serian factibles con las fibras sueltas, como fue puesto en evidencia en la figura 2.

Las consideraciones anteriores permiten ver cómo con fibras Dramix se puede llegar a aspectos de 125 sin los problemas que presentan otras fibras con aspectos menores - del orden de 60 a $80-$ permitiendo por tanto una economia de fibras de hasta el $50 \%$ para iguales resistencias.

El anclaje de los extremos eleva la resistencia a rotura por tracción del hormigón en un $30 \%$ con relación a otras fibras rectas empleadas en el mismo hormigón. Los extremos ofrecen una resistencia muy elsvada al deslizamiento, aunque se hayan formado microfisuras debidas a una deformación grande de la pieza; es decir, se produce un control muy importante de la fisuración, con las ventajas que ello reporta para la durabilidad.

\section{ENSAYOS REALIZADOS EN EL INSTITUTO EDUARDO TORROJA}

Recientemente se ha realizado en el I.E.T. un amplio estudio sobre hormigones reforzados con fibras de acero, de extremos conformados Dramix, a fin de conocer las mejoras que se producian en las caracteristicas mecánicas de hormigones a los que se incorporaron diferentes tipos y cuantias de fibras.
En nuestros ensayos hemos utilizado tres tipos de fibras denominados ZF $30 / 50$, ZP 50/50 y ZC $60 / 80$ y a las que corresponden las siguientes Iongitudes y diámetros: $\ell=30 \mathrm{~mm}, \mathrm{~d}=0,5 \mathrm{~mm}$; $\ell=50 \mathrm{~mm}, \mathrm{~d}=0,5 \mathrm{~mm} ; l=60 \mathrm{~mm}, \mathrm{D}=0,80$ milimetros. Es decir, las fibras tenian aspectos de 60,100 y 75 , respectivamente.

Cada tipo de fibras se ha empleado en cantidades de 40,60 y $80 \mathrm{~kg} / \mathrm{m}^{3}$, equivalentes a $0,50,0,75$ y $1,00 \%$ en volumen, respectivamente.

La dosificación que se adoptó para el hormigón fue:

- Cemento PA-350

$380 \mathrm{~kg}$

- Arena 0/5 mm $800 \mathrm{~kg}$

- Gravilla 5/20 mm $850 \mathrm{~kg}$

- Agua $171 \ell$

El hormigón obtenido con esta dosificación poseía consistencia seca $(1 \mathrm{~cm}$ en cono de Abrams y 10 seg. Vebe) y se diseño asi para observar mejor la influencia de la adición de fibras y las dificultades de su trabajo; a pesar de esto, en ninguno de los casos estudiados se presentaron problemas de formación de bolas ni de incorrecta dispersión de las fibras.

En los resultados de ensayos, dados a continuación, designamos cada hormigón por tres cifras: las dos primeras corresponden al tipo de fibra, y la tercera a la dosificación de fibras en $\mathrm{kg} / \mathrm{m}^{3}$; así, la designación 60/80-40 corresponde a fibras de $\ell=60 \mathrm{~mm}$, d $=0,80 \mathrm{~mm}$ y dosificación de $40 \mathrm{~kg} / \mathrm{m}^{3}$. El hormigón de control sin fibras se designa por $\mathrm{H}-\mathrm{O}$.

La influencia que sobre la docilidad tiene el tipo y dosificación de fibras queda manifestada en el cuadro 1.

\section{CUADRO 1}

\begin{tabular}{|c|c|}
\hline $\begin{array}{c}\text { Hormigón } \\
\text { (designación) }\end{array}$ & $\begin{array}{c}\text { Docilidad } \\
\text { (seg. Vebe) }\end{array}$ \\
\hline$H-O$ & 10 \\
\hline $30 / 50-40$ & 15 \\
$30 / 50-60$ & 18 \\
$30 / 50-80$ & 25 \\
\hline $50 / 50-40$ & 15 \\
$50 / 50-60$ & 28 \\
$50 / 50-80$ & 35 \\
\hline $60 / 80-40$ & 15 \\
$60 / 80-60$ & 21 \\
$60 / 80-80$ & 26 \\
\hline
\end{tabular}




\section{CUADRO 2}

\begin{tabular}{|c|c|c|c|c|c|c|}
\hline \multirow{2}{*}{$\begin{array}{c}\text { Hormigón } \\
\text { (designación) }\end{array}$} & \multirow{2}{*}{$\begin{array}{l}\text { Resistencia a } \\
\text { a compresión } \\
\left(\mathbf{k p} / \mathbf{c m}^{2}\right)\end{array}$} & \multirow{2}{*}{$\begin{array}{c}\text { Módulo de } \\
\text { elasticidad } \\
\left(\mathbf{k p} / \mathbf{c m}^{2} \times 10^{5}\right)\end{array}$} & \multicolumn{2}{|c|}{$\begin{array}{c}\text { Resistencia a tracción } \\
\left(\mathrm{kp} / \mathrm{cm}^{2}\right)\end{array}$} & \multicolumn{2}{|c|}{$\begin{array}{l}\text { Resistencia a flexotracción } \\
\left(\mathrm{kp} / \mathrm{cm}^{2}\right)\end{array}$} \\
\hline & & & 1. ${ }^{\text {a }}$ Fisura & Rotura & 1. ${ }^{\text {a Fisura }}$ & Rotura \\
\hline $\mathrm{H}-\mathrm{O}$ & 237 & 2,42 & - & 18,8 & 38 & 38 \\
\hline $\begin{array}{l}30 / 50-40 \\
30 / 50-60 \\
30 / 50-80\end{array}$ & $\begin{array}{l}244 \\
253 \\
259\end{array}$ & $\begin{array}{l}2,33 \\
2,38 \\
2,76\end{array}$ & $\begin{array}{l}18,4 \\
23,9 \\
26,7\end{array}$ & $\begin{array}{l}23,6 \\
30,1 \\
35,2\end{array}$ & $\begin{array}{l}41 \\
44 \\
48\end{array}$ & $\begin{array}{l}41 \\
44 \\
50\end{array}$ \\
\hline $\begin{array}{l}50 / 50-40 \\
50 / 50-60 \\
50 / 50-80\end{array}$ & $\begin{array}{l}282 \\
311 \\
311\end{array}$ & $\begin{array}{l}2,83 \\
2,72 \\
2,70\end{array}$ & $\begin{array}{l}23,4 \\
27,5 \\
36,2\end{array}$ & $\begin{array}{l}31,8 \\
45,3 \\
54,3\end{array}$ & $\begin{array}{l}45 \\
53 \\
56\end{array}$ & $\begin{array}{l}59 \\
93 \\
98\end{array}$ \\
\hline $\begin{array}{l}60 / 80-40 \\
60 / 80-60 \\
60 / 80-80\end{array}$ & $\begin{array}{l}236 \\
265 \\
270\end{array}$ & $\begin{array}{l}2,51 \\
2,57 \\
2,65\end{array}$ & $\begin{array}{l}23,0 \\
26,2 \\
27,7\end{array}$ & $\begin{array}{l}26,2 \\
35,0 \\
41,8\end{array}$ & $\begin{array}{l}47 \\
49 \\
52\end{array}$ & $\begin{array}{l}66 \\
68 \\
97\end{array}$ \\
\hline
\end{tabular}

Del cuadro 1 se deduce que la docilidad disminuye al aumentar el contenido en fibras dentro de un mismo tipo de ellas. Igualmente se observa, comparando las distintas fibras, que a igualdad de porcentaje de las mismas la docilidad decrece al aumentar el aspecto, y así tenemos que las fibras Dramix ZP $30 / 50$, que tienen aspecto 60 , son más trabajables que las $Z C 60 / 80$ con aspecto 75 y que las ZP 50/50 de aspecto 100. Sin embargo, y a pesar de haber realizado los ensayos con una relación agua-cemento muy baja, la consistencia de todos los hormigones ha sido buena para uso de laboratorio.

En cuanto a las resistencias mecánicas, la determinación se hizo con probetas de $15 \times 30$, para los ensayos de compresión, y de tracción por el método brasileño, mientras que los ensayos de flexión se realizaron sobre probetas de $10 \times 10 \times$ $x 43 \mathrm{~cm}$ con carga centrada y luz entre apoyos de $30 \mathrm{~cm}$. Todos los ensayos se efectuaron a la edad de 28 dias después de un curado normalizado. Los resultados obtenidos, media de tres determinaciones, se recogen en el cuadro $2 \mathrm{y}$, en ellos, puede verse la influencia del tipo de fibras y de su contenido.

El cuadro muestra que la resistencia a compresión experimenta poca variación, si bien se observa un aumento de la misma, con respecto al hormigón patrón, al crecer el contenido de fibras llegando a ser este aumento del $31.2 \%$ para las fibras $50 / 50$, en proporción de $80 \mathrm{~kg} / \mathrm{m}^{3}$. Se ve, igualmente, que los modulos de elasticidad apenas difieren entre si, ejerciendo muy poca influencia las fibras sobre ellos.

En la resistencia a tracción se observa un fuerte incremento al aumentar el contenido de fibras, especialmente en las fibras de mayor aspecto, llegándose a incrementos del $189 \%$.
Los resultados a flexotracción muestran una tendencia parecida a los de tracción y así se observa que, para un contenido nulo de fibras, sobreviene la rotura a una tensión de $38 \mathrm{kp} / \mathrm{cm}^{2}$. En los hormigones con fibras $50 / 50$, en proporción de $80 \mathrm{~kg} / \mathrm{m}^{3}$, la primera fisura ocurre con una tensión del 48,3\% mayor y la rotura con un $157 \%$ más elevada. Se observa, igualmente, la gran eficacia de las fibras de mayor aspecto en la resistencia a flexotracción y la importancia que tienen los hormigones reforzados de fibras -en su empleo- en pavimentos industriales, de carreteras y de aeropuertos, asi como en revestimientos gunitados de túneles, taludes, canales y piscinas, y, en general, en todos los hormigones sometidos a flexión.

Unas características muy interesantes -en muchas aplicaciones- son la tenacidad y la resistencia al impacto de los hormigones. El índice de tenacidad determinado de acuerdo con el $\mathrm{ACl}$ es la relación que existe entre el área comprendida bajo la curva carga-flecha y la ordenada que pasa por el punto de flecha $1,9 \mathrm{~mm}$ y el área comprendida bajo la misma curva y la ordenada que pasa por la carga correspondiente a la aparición de la primera fisura (Fig. 8).

La resistencia al impacto se ha determinado de acuerdo con el ACl sobre rodajas de $6,5 \mathrm{~cm}$ de altura cortadas de probetas de $15 \times 30$. Los golpes de impacto se dieron sobre una esfera de $63 \mathrm{~mm}$ de diámetro colocada en un alojamiento tubular del dispositivo de la figura 9. La energía que se suministró en cada golpe fue de $10 \mathrm{kgm}$, dándose la resistencia al impacto como el número de golpes preciso para que la probeta rompa tocando tres de los cuatro soportes que lleva el montaje. En el cuadro 3 se indican los resultados obtenidos, media de tres determinaciones. 

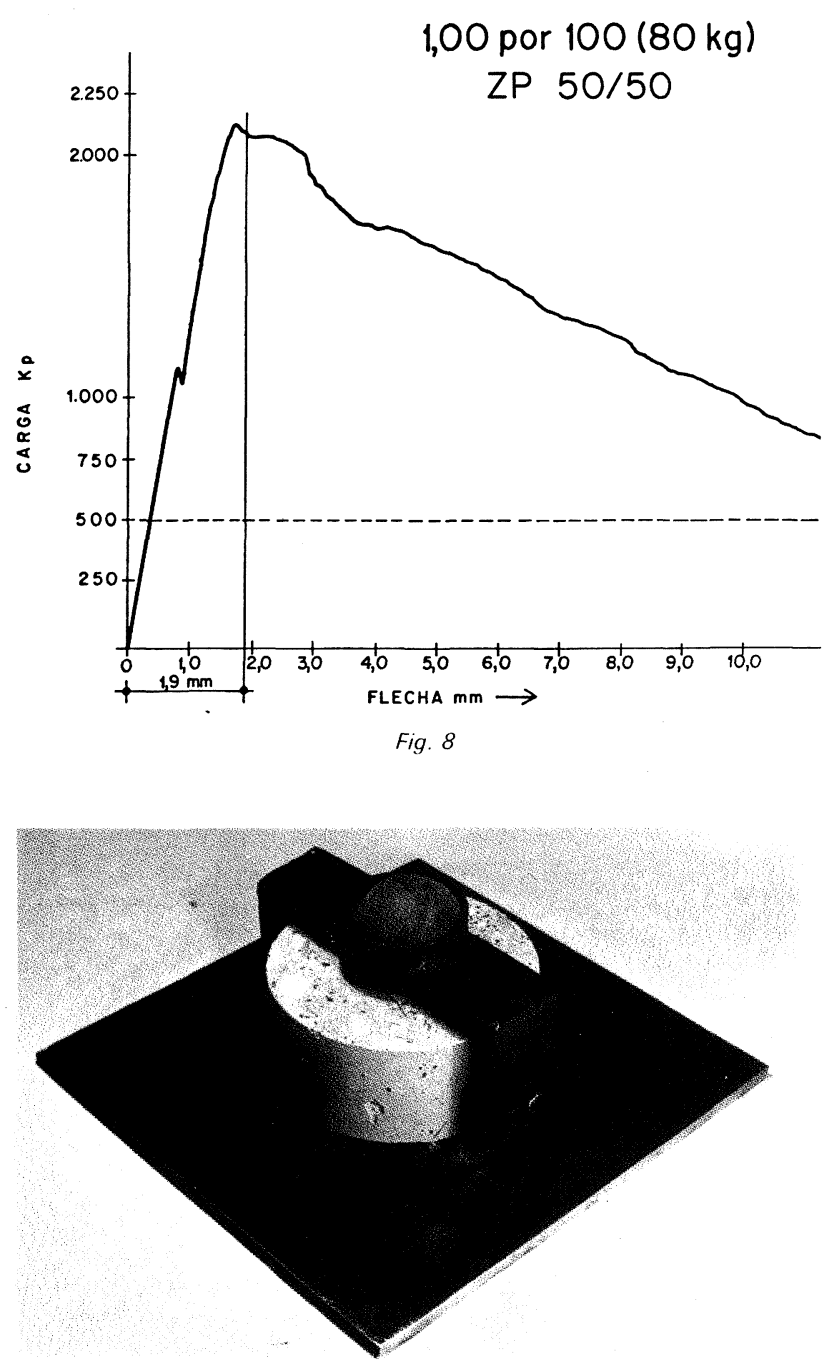

Fig. 9

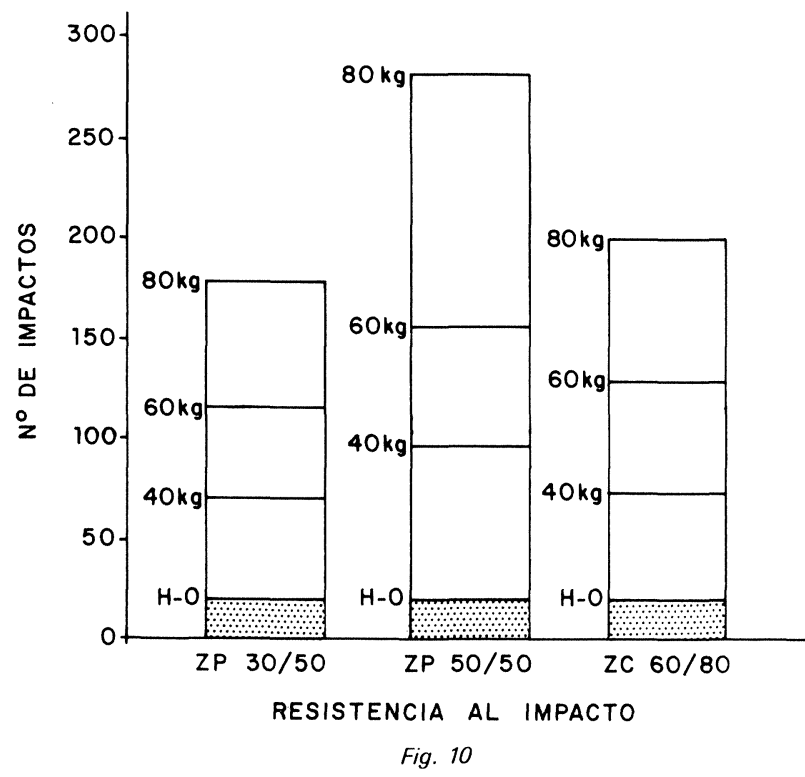

Como se ve en el cuadro 3 , el indice de tenacidad llega a ser 10 veces superior al del hormigón tradicional, lo que indica la gran capacidad de absorción de energía que poseen estos hormigones. En el gráfico de la figura 8 puede observarse cómo las deformaciones pueden ser muy elevadas antes de llegar a la rotura cómo los hormigones pueden seguir soportando cargas.

Con respecto a la resistencia al impacto vemos que, con el empleo de fibras Dramix 50/50, puede incrementarse ésta en un $1.310 \%$; esto, unido al incremento del $780 \%$ que para el indice de tenacidad proporcionan las mismas fibras, hace que estos hormigones sean muy adecuados en pavimentos industriales, de carreteras y de aeropuertos, así como en muchas aplicaciones militares. (Fig. 10).

Por último, cabe reseñar los ensayos de fatiga a flexión realizados sobre probetas de $10 \times 10 \times 43$ centímetros, aplicando una carga dinámica en el centro de la probeta con una frecuencia de 500 c/min, y con una carga positiva oscilante entre 300 y $600 \mathrm{kp}$ para los hormigones con fibras ZP $30 / 50$; de 300 a $750 \mathrm{kp}$ para los de fibras ZP $50 / 50$, y de 300 a $850 \mathrm{kp}$ para los de fibras ZC $60 / 80$. El tope máximo de ciclos previsto fue de $1 \times 10^{6}$. En el cuadro 4 figuran los valores hallados.

\section{CUADRO 3}

\begin{tabular}{|c|c|c|}
\hline $\begin{array}{c}\text { Hormigón } \\
\text { (designación) }\end{array}$ & $\begin{array}{l}\text { Indice de } \\
\text { tenacidad }\end{array}$ & $\begin{array}{l}\text { Resistencia } \\
\text { al impacto } \\
\text { (n. }{ }^{\circ} \text { golpes) }\end{array}$ \\
\hline $\mathrm{H}-\mathrm{O}$ & 1,00 & 20 \\
\hline $30 / 50-40$ & 4,32 & 72 \\
\hline $30 / 50-60$ & 6,59 & 116 \\
\hline $30 / 50-80$ & 10,31 & 178 \\
\hline $50 / 50-40$ & 4,64 & 98 \\
\hline $50 / 50-60$ & 7,12 & 156 \\
\hline $50 / 50-80$ & 8,80 & 282 \\
\hline $60 / 80-40$ & 6,33 & 75 \\
\hline $60 / 80-60$ & 6,93 & 132 \\
\hline $60 / 80-80$ & 7,27 & 203 \\
\hline \multicolumn{3}{|c|}{ CUADRO 4} \\
\hline $\begin{array}{c}\text { Hormigón } \\
\text { (designación) }\end{array}$ & & $\begin{array}{c}\text { Ciclos hasta } \\
\text { rotura }\end{array}$ \\
\hline $\mathrm{H}-\mathrm{O}$ & & 17.200 \\
\hline $30 / 50-40$ & & 52.000 \\
\hline $30 / 50-60$ & & 78.800 \\
\hline $30 / 50-80$ & & 190.000 \\
\hline $50 / 50-40$ & & $>1.000 .000$ \\
\hline $50 / 50-60$ & & $>1.000 .000$ \\
\hline $50 / 50-80$ & & $>1.000 .000$ \\
\hline $60 / 80-40$ & & $>1.000 .000$ \\
\hline $60 / 80-60$ & & $>1.000 .000$ \\
\hline $60 / 80-80$ & & $>1.000 .000$ \\
\hline
\end{tabular}


La resistencia a fatiga por flexión es muy elevada, como puede verse en el cuadro 4 , especialmente en los hormigones confeccionados con fibras de mayores aspectos, 75 y 100 . En ambos, a pesar de haberse aplicado, en algunos casos, cargas superiores al $80 \%$ de la carga de primera fisura, se llegó al tope de ciclos previsto, quedando ligeramente fisuradas las probetas al final de los ensayos.

\section{APLICACIONES}

Los hormigones reforzados con fibras de acero han alcanzado ya su mayoria de edad, colocándose actualmente en obra - en el mundo- muchos miles de metros cúbicos al año algunos de los cuales corresponden a España. Estos hormigones se están utilizando ampliamente en prefabricación y construcción industrializada, en pavimentos y soleras de fábricas y almacenes (por los que han de circular carretillas pesadas), en pavimentos de carreteras y aeropuertos, $y$, especialmente, en su recrecido cuando están deteriorados, formando "overlays" unidos o no al pavimento existente; en recipientes para reactores nucleares; en depósitos para líquidos; en estructuras de seguridad, cajas fuertes, etc.; en el gunitado de túneles, canales y taludes; en revestimientos refractarios para hornos metalúrgicos; y en determinadas partes de la industria del cemento mediante el empleo de fibras de acero inoxidable. Debido a su gran resistencia al impacto y fatiga su empleo en el campo militar es cada vez mayor, utilizándose en pavimentos para carros de combate; aeropuertos y helipuertos; zonas de lanzamiento de cohetes y misiles; polvorines y factorias de pólvora y explosivos; refugios y puestos de mando fortificados; etc.

Las aplicaciones anteriores son consecuencia de la capacidad que tienen los hormigones reforzados de fibras de acero para resistir eficazmente determinadas acciones, especialmente las que se producen en las aplicaciones antes reseñadas y en aquellas otras en las que se precise:

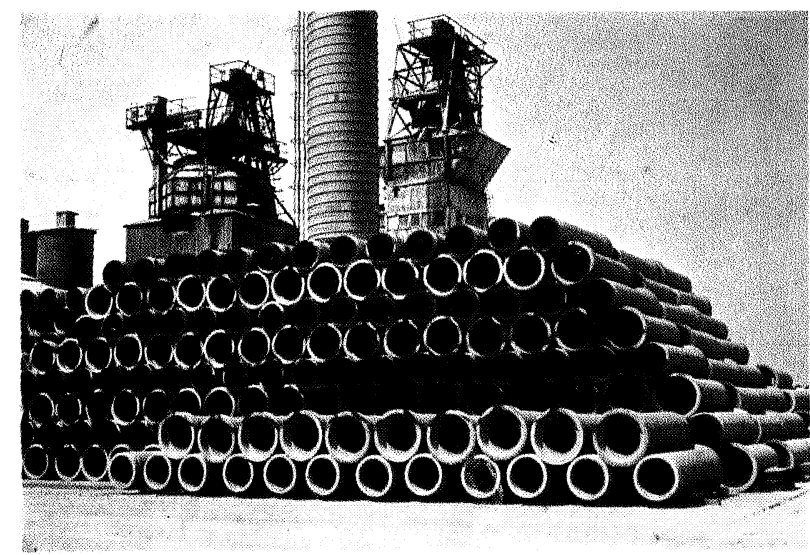

Fig. 11
- mejora del comportamiento a flexotracción

- aumento de la resistencia a tracción,

- incremento de la resistencia a rotura,

- reducción de la deformación bajo cargas mantenidas,

- ligero aumento de resistencia a compresión,

- fuerte absorción y disipación de energía antes de romper,

- elevada resistencia al impacto y a choque,

- gran resistencia a fatiga dinámica,

- fisuración controlada,

- mejora de la adherencia a las barras de armado tradicional,

- mayor durabilidad como consecuencia de menor fisuración,

- resistencia elevada a los choques térmicos.

En elementos prefabricados se están empleando en la fabricación de tuberias (Fig. 11) debido a que, con las fibras, se pueden reducir espesores a la vez que se mejora la impermeabilidad; esta aplicación está fundada, por otra parte, en la exigencia de los reglamentos de diferentes paises en los cuales los tubos, a partir de determinados diámetros, tengan que llevar una armadura de seguridad.

En construcción industrializada (Figs. 12 y 13) permiten reducir espesor de paredes, evitando la colocación de cualquier tipo de armaduras y haciendo innecesaria la presencia de armaduras tradicionales incluso en las zonas de dinteles de puertas y ventanas. Con el empleo de estos hormigones no se presentan problemas de fisuración (Fig. 14).

En pavimentos, donde la resistencia a flexotracción - y a veces a impacto- es fundamental, se emplean las fibras cada vez más. Son muchos los pavimentos industriales en los que se han utilizado, sin necesidad, en gran número de casos, de realizar juntas. En España se han hecho miles de metros cuadrados de pavimentos en naves industriales; naves de mantenimiento de helicópteros; pavimentos para parques de contenedores; suelos de talleres en fábricas de automóviles; etc. Aparte de la ventaja de separar más, e incluso eliminar las juntas, se tiene la de un espesor más reducido y una vida útil que puede ser de cinco a ocho veces la de un pavimento tradicional.

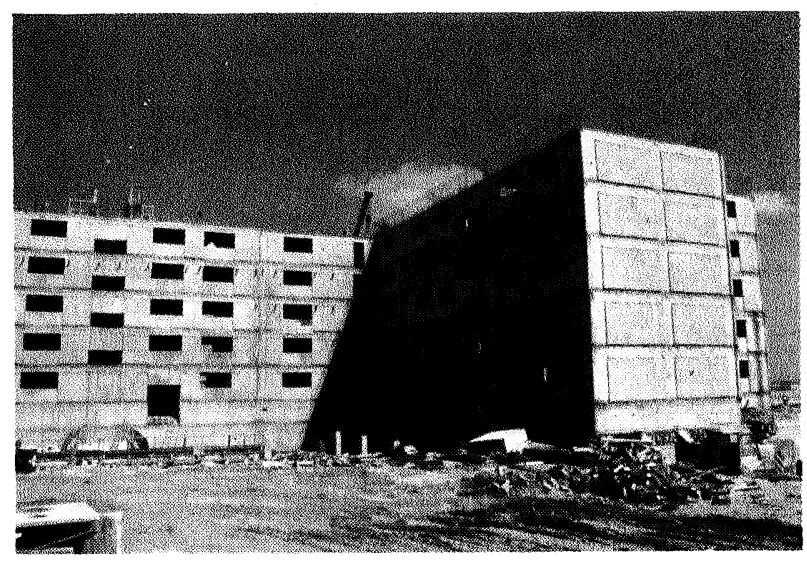

Fig. 12 


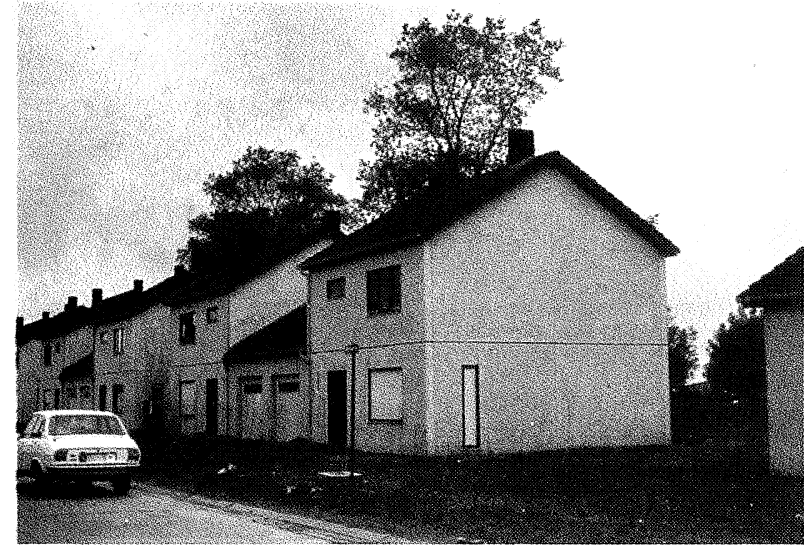

Fig. 13

El aumento de resistencia a flexotracción, el control de la fisuración, la resistencia a la fatiga dinámica y la posibilidad de hacer juntas cada 15 metros o más (e incluso, de no hacerlas) trae consigo el que los hormigones reforzados con fibras se utilicen mucho en pavimentos de autopistas y carreteras, bien en la totalidad de su espesor, bien en forma de recrecidos sobre pavimentos rigidos o flexibles deteriorados, con la ventaja adicional de requerir un espesor reducido de 7 a $10 \mathrm{~cm}$ y de poder colocarse con cualquier extendedora tradicional o simplemente con reglas vibrantes (Figuras 15,16 y 17). Actualmente, la técnica de los recrecidos con este tipo de hormigones se está utilizando cada vez más, debido a las grandes ventajas técnicas y económicas que presenta.

Otra de las ventajas que presenta el hormigón de fibras es poder colocarse en obra mediante gunitado. Empleando áridos de hasta $10 \mathrm{~mm}$, con fibras de 30 a $50 \mathrm{~mm}$ de longitud, se han gunitado con éxito túneles, taludes, canales y piscinas ( $\mathrm{Fi}$ gura 18). La principal ventaja que presentan estos hormigones, en el revestimiento de túneles, radica en la rapidez de ejecución al eliminar la colocación de la malla electrosoldada -labor siempre lenta y engorrosa - en las superficies tan irregulares de un túnel. Por otra parte, la capa de gunita puede adaptarse perfectamente a las superficies, con lo cual se tiene una mayor economía en hormigón. Al estar toda la capa proyectada atada por las fibras, no se producen desprendimientos y la capacidad de absorción de esfuerzos queda incrementada.

El gunitado, utilizando fibras de acero inoxidable, es una técnica frecuente actualmente en los revestimientos refractarios de industrias metalúrgicas, de cementos y petroquimicas. Los revestimientos refractarios armados con fibras poseen, gracias a la trabazón que éstas proporcionan, una gran resistencia frente a los choques térmicos, a la vez que una fuerte resistencia a la abrasión. Revestimientos de recuperadores de calor en fábricas de cemento, que periódicamente habia que cambiar cada uno o dos años, al incorporar fibras Dramix inoxidables han incrementado su vida en cinco ve-
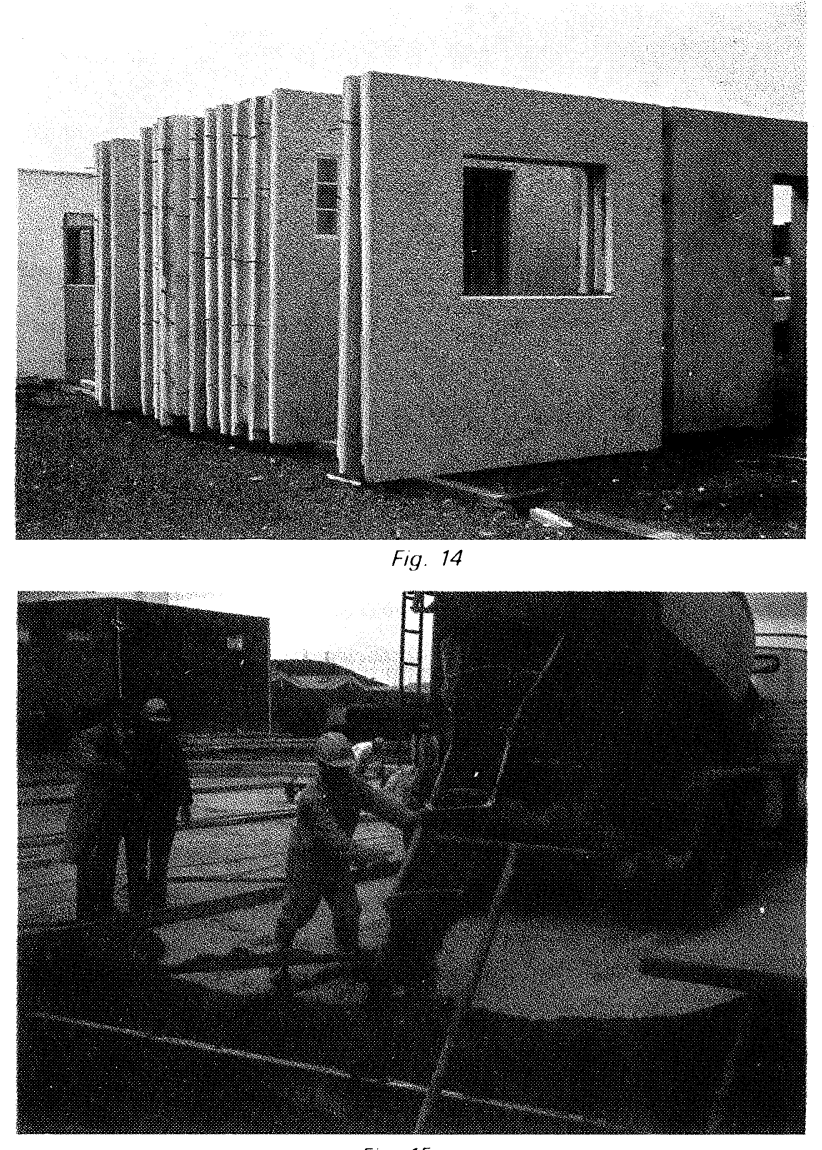

Fig. 15

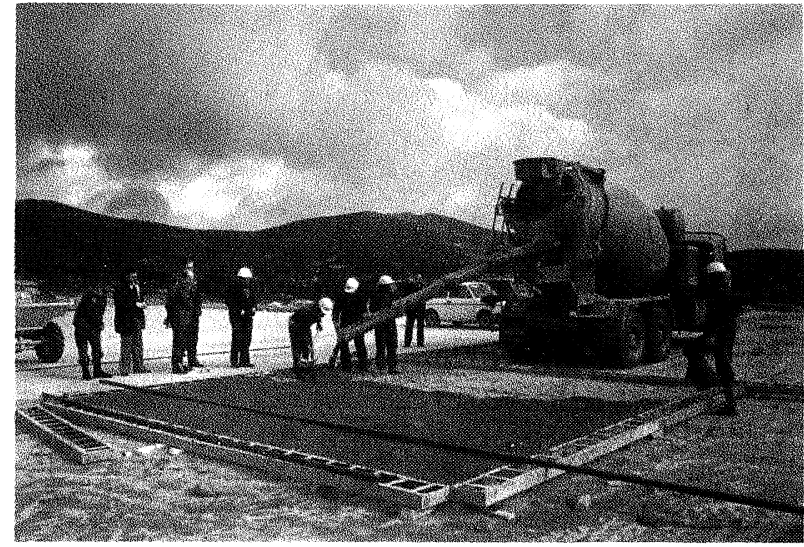

Fig. 16

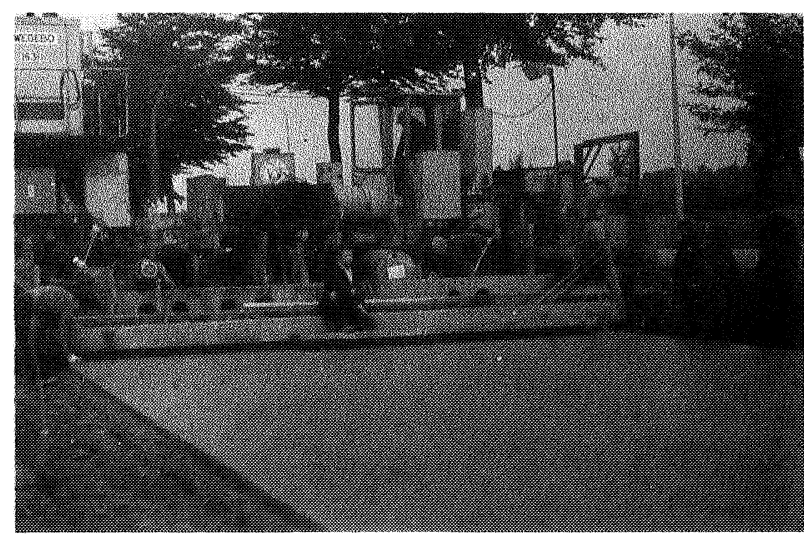

Fig. 17 


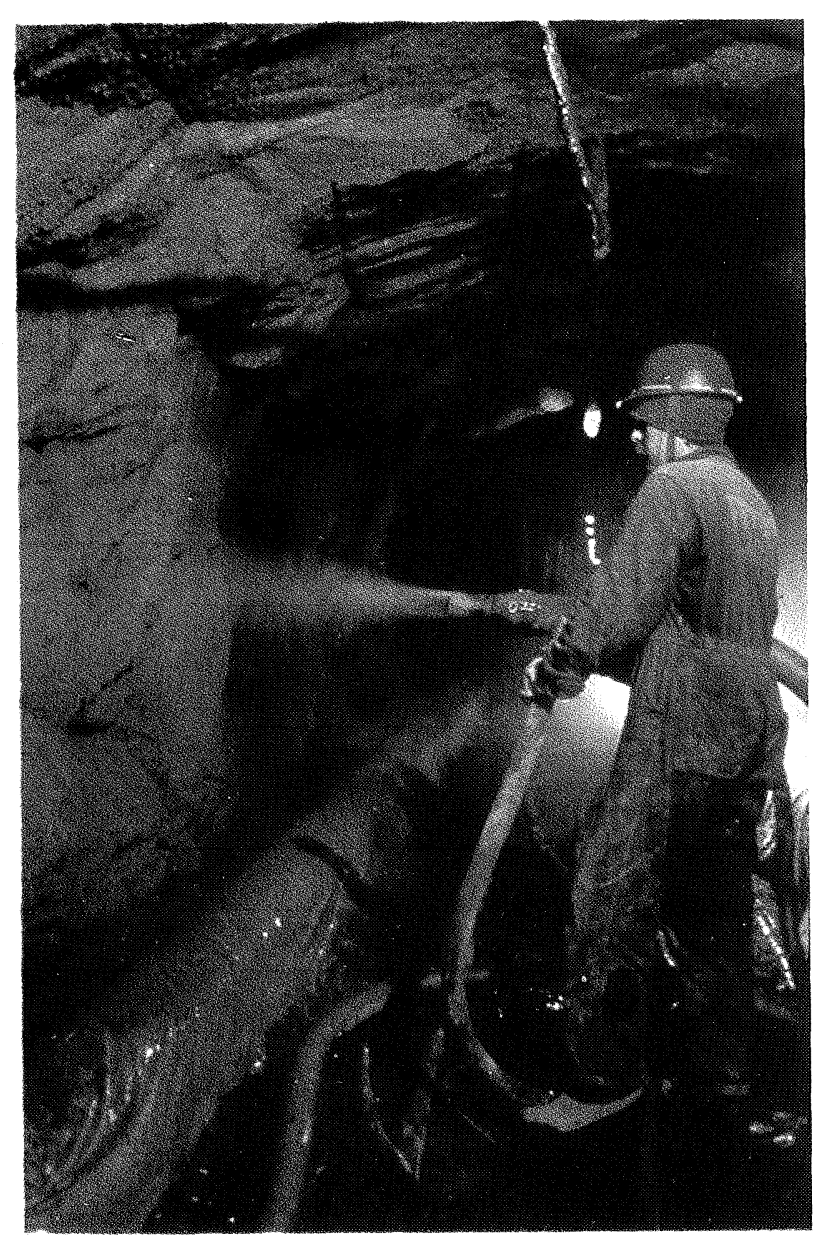

Fig. 18

ces. El utilizar fibras inoxidables tiene como finalidad evitar las fuertes corrosiones que se producirian en fibras normales, al estar sometidas a atmósferas tan agresivas como las que se suelen existir en los hornos.

Tal vez una aplicación de las más interesantes de los hormigones de fibras de acero esté en el campo de los pavimentos de aeropuertos.

Los primeros ensayos se realizaron por la U.S. Army Construction Engineering Research Laboratory (CERL) y consistieron: uno, en un pavimento de hormigón con fibras; y otro, en un recrecido sobre un pavimento deteriorado de hormigón. Ambos tramos de ensayo realizados a escala natural se sometieron a las pruebas de un tráfico simulado C-5A con carga de 340 t. El avión C-5A se emplea en aeropuertos militares de carga media y posee tres trenes de aterrizaje, con doce ruedas en cada uno de los dos principales y cuatro en el del morro; sobre cada rueda del tren gravitan 13,6 $\mathrm{t}$. Para simular el aterrizaje se aplicaba el tren sobre cinco lineas paralelas separadas entre si un ancho de 5 metros.

En otra zona se aplicó un tren tándem con 18,9 t equivalente al del Yumbo 747.
La losa de hormigón con fibras de acero tenia un espesor de $150 \mathrm{~mm}$ y descansaba sobre una base de arena ligeramente compactada. Para comparar, la U.S. Army Waterway Experiment Station construyó también una losa de hormigón tradicional de $250 \mathrm{~mm}$ de espesor sobre una base de arena bien compactada. El recrecido de hormigón de fibras se extendio sobre la losa anterior después de haberla ensayado, con un espesor de $100 \mathrm{~mm}$.

El pavimento de fibras sobre base débil era de espesor aproximadamente mitad al de hormigón tradicional sobre base bien compactada. El primero presento la primera fisura a las 700 cargas de tráfico, mientras que el tradicional la presentaba a las 40 cargas y estaba fuera de servicio a las 950 . El hormigón de fibras alcanzó 8.700 cargas y sólo presentaba fisuras capilares.

El recrecido u "Overlay" de $100 \mathrm{~mm}$ se construyó sobre el pavimento de hormigón tradicional antes ensayado (totalmente deteriorado) presentando sólo algunas fisuras capilares a las 6.900 cargas de tráfico del tren C-5A. La primera fisura apareció en él a las 900 cargas y la segunda, a las 1.400 cargas.

Bajo la dirección de estos laboratorios se realizó la primera prueba a escala natural en el aeropuerto de Tampa, en forma de recrecidos sobre pavimentos deteriorados, siendo los recrecidos de $150 \mathrm{~mm}$ de espesor en pistas de "runway" y de $100 \mathrm{~mm}$ en las de "taxiway". Los resultados obtenidos fueron totalmente satisfactorios.

Con posterioridad a estos ensayos se hicieron los pavimentos de la base de Nolfort; ampliaciones 0 reparaciones con pavimento total o recubrimientos en los aeropuertos de Las Vegas, La Guardia, John Kennedy, etc. Actualmente se ha finalizado el aeropuerto de Denver -Colorado- (Figs. 19 y 20). En España, últimamente, se ha realizado una aplicación importante en el aeropuerto de Palma de Mallorca.

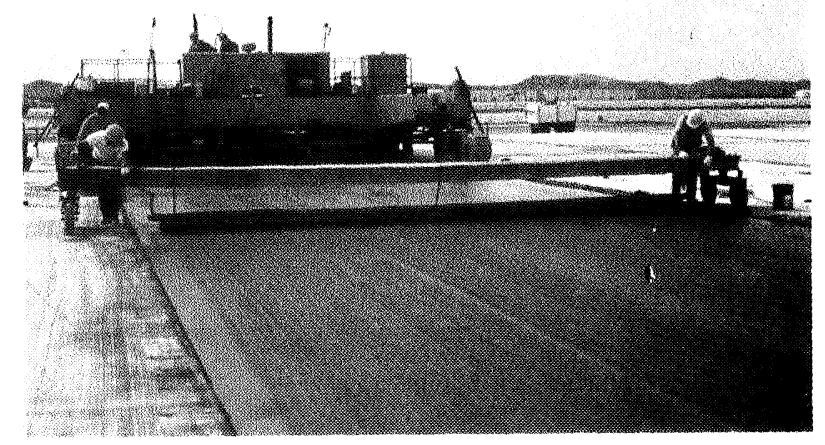

Fig. 19 


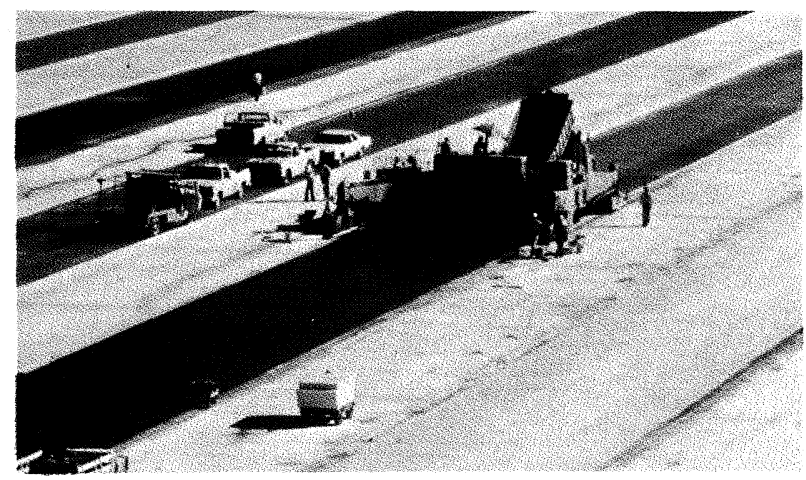

Fig. 20

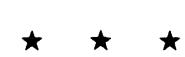

En la actualidad podemos decir que con el empleo de las fibras de acero se han resuelto muchos de los inconvenientes que tiene el hormigón, los cuales señalábamos al principio de este trabajo. Además, tales inconvenientes se han resuelto con la ventaja adicional de economia en mano de obra, al evitar en muchas ocasiones parte o toda la armadura tradicional, especialmente cuando ésta tiene la misión de controlar la fisuración.

El empleo de fibras de acero, en los hormigones, combinado con el de superplastificantes en unos casos y látex en otros, puede dar como resultado hormigones con unas características muy diferentes a los tradicionales, en los cuales hayan desaparecido muchos de esos inconvenientes o desventajas que al principio apuntábamos en el hormigón tradicional; inconvenientes que hay que tratar de eliminar para conseguir que este noble material esté más acorde con los tiempos actuales.

\section{publicación del i.e.t. c.c.}

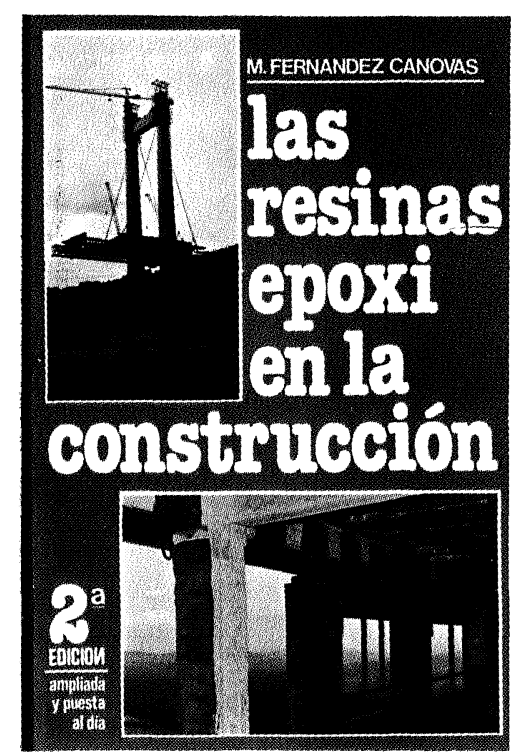

Manuel Fernández Cánovas

Dr. Ingeniero de Construcción

Este libro, el primero en lengua castellana sobre resinas epoxi aplicadas a la construcción, está dirigido a arquitectos, ingenieros, constructores y aplicadores. En él, sobre una reducida base teórica imprescindible, se asienta toda una extensa gama de aplicaciones de gran interés.

El autor trabaja desde hace muchos años en el campo de la investigación, especialmente en el estudio de refuerzos y reparaciones estructurales realizados con resinas epox.

Con un lenguaje sencillo se tocan todos los problemas que pueden presentarse en la construcción y en los que la solución puede radicar en el correcto empleo de las resinas epoxi.

Se estudian los componentes de las formulaciones epoxi, sus propiedades fisicas y quimicas, y aplicaciones, deteniéndose, detalladamente, en las siguientes:

Unión de hormigón fresco a hormigón endurecido. - Unión de hormigones entre si.-Inyecciones de fisuras y grietas. - Unión de acero a hormigón. - Barnices y pinturas. - Las combinaciones brea-epoxi. - Revestimientos de depósitos alimenticios. - Sellado de superficies cerámicas. - Protección de tubos. - Los suelos epoxi en sus diferentes variantes. - Terrazo epoxi. - Reparación de baches. - Reparación de desperfectos en estructuras. - Reparación de carreteras de hormigón. - Juntas elásticas. - Guardacantos de tableros de puentes. - Refuerzos de pilares, vigas, forjados y zapatas, etc. - Consolidación de suelos. - Anclajes. - Protección de aceros en pretensado.

Se termina con unos capitulos dedicados a la limpieza y preparación de las superficies según los materiales a unir; al control del estado superficial de èstos: a las condiciones de temperatura de aplicación; limpieza de los útiles de tra métodos de ensayo de sistemas y aplicaciones epoxidicas.

Un volumen encuadernado en cartoné plastificado con lomo de tela, de $17 \times 24 \mathrm{~cm}$, compuesto de 334 páginas y 158 figuras y fotografias.

Madrid, 1981

Precios: España, 1.700 ptas.: extranjero. S USA 24.00 